\title{
The Future of Mesothelioma Research: Basic Science Research
}

\author{
Vanessa S. Fear, Alistair M. Cook, and Scott A. Fisher
}

\section{Introduction}

Much of our current understanding of the causes, biological mechanisms, risk factors, and potential treatments for mesothelioma are derived not from the clinic, but from basic research that involves a mixture of in vitro work using cell lines grown in the lab and in vivo experiments where treatments are explored in a variety of animal models of mesothelioma (predominantly mice). This section gives an overview of the cutting-edge preclinical research currently being performed in the field. Pre-clinical models are discussed in the context of conventional therapies, followed by new and emerging treatments.

\section{$2 \quad$ Pre-clinical Models}

Clinical studies of mesothelioma are somewhat limited by the low numbers of patients presenting at any one location. Therefore, establishment of cell lines and disease-representative animal models has been important for our understanding of the development, biology, and progression of this aggressive disease. Key aspects include isolation of human tumour cell lines and development of asbestos-derived mesothelioma cell lines from mice, plus the establishment of models of solid tumours, orthotopic models of local and metastatic disease, and long-term asbestos exposure. Each model has specific advantages and limitations as discussed below.

\footnotetext{
V. S. Fear $(\bowtie) \cdot$ A. M. Cook · S. A. Fisher

National Centre for Asbestos Related Diseases, The University of Western Australia, School of Biomedical Sciences, Perth, WA, Australia

e-mail: Vanessa.Fear@telethonkids.org.au; alistair.cook@uwa.edu.au; scott.fisher@uwa.edu.au
} 


\subsection{Mesothelioma Cell Lines}

In early studies, human malignant mesothelioma cell lines were used extensively to study drug susceptibility, cytokine production, and response of immune effector cells in vitro. Furthermore, these cell lines helped define various phenotypic and genetic characteristics of human tumours, e.g. epithelioid or sarcomatoid (Table 18.1).

Human cell lines provided information regarding the resistance of mesothelioma to cytotoxic drugs such as actinomycin D, cisplatin, etoposide, methotrexate, 5' fluorouracil, mitomycin $\mathrm{C}$, and vinblastine. Further human cell line studies determined the response of mesothelioma cells to cytokines including TNF $\alpha, \operatorname{IFN} \gamma$, and IFN $\alpha$, indicating reduced proliferation of some cell lines. Later notable immunology studies included stimulation of cytotoxic T cells or natural killer (NK) cells with cytokines to stimulate tumour cell killing. This led to the notion that immunotherapeutic approaches to mesothelioma may be more effective in vivo rather than assayed by direct anti-tumour activity on cell lines.

Cell monolayer cultures are easy to handle and suitable for large-scale drug testing, but drug sensitivity in vitro often does not translate to the clinic. A potential limitation of research using human cell lines is that continued long-term culturing may result in highly selected clonal tumour cell populations that only partially represent the original tumour.

To overcome such issues, recent research has focused on the use of 3D spheroid cultures, which more closely mimic solid tumours (Schunselaar et al. 2016). Mesothelioma is particularly resistant to chemotherapy, an outcome not always accurately reflected when using in vitro monolayer cultures. Conversely, 3D spheroid cultures have shown chemotherapy resistance profiles similar to that observed in patients. However, the use of 3D cultures is still limited by the intrinsic complications associated with quantifying cell survival.

Table 18.1 Mesothelioma cell lines

\begin{tabular}{|c|c|c|c|}
\hline Cell lines & Phenotype/source & Species & References \\
\hline NO-36 & Pleural effusion & Human & \multirow[t]{5}{*}{ Manning et al. (1991) } \\
\hline JU-77 & Pleural effusion & Human & \\
\hline LO-68 & Pleural effusion & Human & \\
\hline ONE-58 & Pleural effusion & Human & \\
\hline DeHI28(M) & Pleural effusion & Human & \\
\hline REN MM cell line & Primary tumour & Human & Taguchi et al. (1993) \\
\hline $\begin{array}{l}\mathrm{AB} 1, \mathrm{AB} 2, \mathrm{AB} 12, \\
\mathrm{AB} 13, \mathrm{AB} 22\end{array}$ & Sarcomatoid & $\begin{array}{l}\text { Mouse BALB/cArc } \\
\left(\mathrm{H}-2^{\mathrm{d}}\right)\end{array}$ & \multirow[t]{2}{*}{ Davis et al. (1992) } \\
\hline $\begin{array}{l}\text { AC } 14, \text { AC } 16, \text { AC } 24, \\
\text { AC28, AC29, AC } 31, \\
\text { AC } 32, \text { AC } 34, \text { AC } 36\end{array}$ & Sarcomatoid & Mouse CBA $\left(\mathrm{H}-2^{\mathrm{k}}\right)$ & \\
\hline AE17 & Sarcomatoid & Mouse C57BL/6 (H-2 $\left.{ }^{\mathrm{b}}\right)$ & Jackaman et al. (2003) \\
\hline 40 & $\begin{array}{l}\text { Highly invasive, } \\
\text { metastatic }\end{array}$ & Mouse C57BL/6 & Goodglick et al. (1997) \\
\hline
\end{tabular}


Other in vitro models include primary cell culture using single cells isolated from patients that are cultured for a short period of time. These cultures, often taken from pleural effusions, more closely represent the original tumour in cell complexity, cytology, and cellular biology. In some hands, primary tumour cultures have resistance to drug treatment mirroring the clinical setting (Schunselaar et al. 2016). However, establishing primary tissue cultures is often difficult, and in vitro resistance to drug treatment is extremely variable between patients.

\subsection{Animal Models of Mesothelioma}

The refractive nature of malignant pleural mesothelioma to aggressive trimodal treatment (surgery, chemotherapy, and/or radiation) has patient survival at only 1-2 years depending on stage and histology at time of diagnosis (Rusch et al. 2012). Accordingly, new treatment strategies are urgently required, and here we discuss current preclinical research efforts. Early studies in animal models assessed the carcinogenicity of different fibre types, with identification of asbestos fibre exposure leading to mesothelioma. Other animal models include xenograft models with human tissue, orthotopic models at the site of mesothelioma formation, solid tumour models, and genetic predisposition models. Preclinical mesothelioma models are listed in Table 18.2.

Table 18.2 Features of preclinical models and their application

\begin{tabular}{|c|c|c|c|c|c|}
\hline Model & Applications & $\begin{array}{l}\text { Tumour } \\
\text { mimic }\end{array}$ & Time & Benefits & Disadvantages \\
\hline \multicolumn{6}{|c|}{ Cell line models } \\
\hline Monolayer & $\begin{array}{l}\text { Large-scale } \\
\text { drug testing }\end{array}$ & Low & Short & $\begin{array}{l}\text { High } \\
\text { throughput }\end{array}$ & $\begin{array}{l}\text { Lack of immune system, } \\
\text { poor translation }\end{array}$ \\
\hline Spheroids & & Yes & Long & $\begin{array}{l}\text { Mimics tumour } \\
\text { response }\end{array}$ & $\begin{array}{l}\text { Technically demanding } \\
\text { and difficult to quantitate }\end{array}$ \\
\hline \multicolumn{6}{|c|}{ Tumour primary tissue culture } \\
\hline Monolayer & $\begin{array}{l}\text { Drug } \\
\text { sensitivity }\end{array}$ & Low & Short & $\begin{array}{l}\text { Patient tumour } \\
\text { cells }\end{array}$ & $\begin{array}{l}\text { Lack of immune system, } \\
\text { poor translation }\end{array}$ \\
\hline 3D spheroids & Drug testing & Yes & Long & Mimics tumour & $\begin{array}{l}\text { Technically demanding } \\
\text { and difficult to quantitate }\end{array}$ \\
\hline $\begin{array}{l}\text { Tumour } \\
\text { biopsy }\end{array}$ & Drug testing & Yes & Long & $\begin{array}{l}\text { Mimics } \\
\text { tumour; stromal } \\
\text { cells }\end{array}$ & \\
\hline \multicolumn{6}{|c|}{ Asbestos-induced models } \\
\hline Intraperitoneal & $\begin{array}{l}\text { Disease } \\
\text { development }\end{array}$ & Yes & Long & $\begin{array}{l}\text { Technically } \\
\text { easy }\end{array}$ & $\begin{array}{l}20-30 \% \text { incidence; tumour } \\
\text { hard to measure; peritoneal } \\
\text { mesothelioma represents } \\
10-20 \% \text { of patient disease }\end{array}$ \\
\hline Intrapleural & $\begin{array}{l}\text { Disease } \\
\text { development }\end{array}$ & Yes & Long & $\begin{array}{l}\text { Local invasion; } \\
\text { ascites } \\
\text { development; } \\
\text { aetiology }\end{array}$ & $\begin{array}{l}\text { Technically difficult; long } \\
\text { latency; development of } \\
\text { adenocarcinoma/lung } \\
\text { cancer; difficult to measure }\end{array}$ \\
\hline
\end{tabular}


Table 18.2 (continued)

\begin{tabular}{|c|c|c|c|c|c|}
\hline Model & Applications & $\begin{array}{l}\text { Tumour } \\
\text { mimic }\end{array}$ & Time & Benefits & Disadvantages \\
\hline \multicolumn{6}{|c|}{ Xenograft models } \\
\hline & Drug testing & Yes & Long & $\begin{array}{l}\text { Human cells } \\
\text { used }\end{array}$ & $\begin{array}{l}\text { No immune system; } \\
\text { irrelevant anatomical site }\end{array}$ \\
\hline \multicolumn{6}{|c|}{ Mouse orthotopic models } \\
\hline Intrapleural & $\begin{array}{l}\text { Drug testing; } \\
\text { tumour } \\
\text { development }\end{array}$ & Yes & Short & $\begin{array}{l}\text { Anatomically } \\
\text { relevant site }\end{array}$ & $\begin{array}{l}\text { High level of technical } \\
\text { expertise; risk of } \\
\text { complications; difficult to } \\
\text { measure }\end{array}$ \\
\hline \multicolumn{6}{|c|}{ Mouse solid tumour models } \\
\hline & Drug testing & Yes & Short & $\begin{array}{l}\text { Immune } \\
\text { system; high } \\
\text { throughput }\end{array}$ & $\begin{array}{l}\text { Irrelevant anatomical site/ } \\
\text { microenvironment }\end{array}$ \\
\hline \multicolumn{6}{|c|}{ Genetic predisposition mouse models } \\
\hline$N F 2+/-\mathrm{KO}$ & $\begin{array}{l}\text { Disease } \\
\text { development }\end{array}$ & Yes & Mid & $\begin{array}{l}\text { Ascites; tumour } \\
\text { dissemination } \\
\text { and invasion; } \\
\text { use of asbestos }\end{array}$ & $\begin{array}{l}\text { Artificial bias in the gene } \\
\text { setting; only } 85 \% \text { of mice } \\
\text { develop disease; cannot } \\
\text { measure tumour directly }\end{array}$ \\
\hline$P 53+/-\mathrm{KO}$ & $\begin{array}{l}\text { Disease } \\
\text { development }\end{array}$ & Yes & Long & $\begin{array}{l}\text { Local tissue } \\
\text { invasion and } \\
\text { lymph node } \\
\text { metastases; use } \\
\text { of asbestos }\end{array}$ & $\begin{array}{l}\text { Not all mice develop } \\
\text { disease; not a key gene for } \\
\text { mesothelioma; formation } \\
\text { of spontaneous tumours }\end{array}$ \\
\hline $\begin{array}{l}\text { NF2,P53, } \\
p 16^{\operatorname{Ink} 4 a} / p 19^{\text {Arf }} \\
\mathrm{KO}\end{array}$ & $\begin{array}{l}\text { Disease } \\
\text { development }\end{array}$ & Yes & Short & $\begin{array}{l}\text { Inducible P53 } \\
\text { expression }\end{array}$ & $\begin{array}{l}\text { Mesothelioma induced } \\
\text { without asbestos; high } \\
\text { tumour incidence } \\
(80-100 \%) \text { but not all } \\
\text { mesothelioma }\end{array}$ \\
\hline $\begin{array}{l}\text { MexTAg } \\
\text { (SV40 large } \\
\text { T antigen) }\end{array}$ & $\begin{array}{l}\text { Asbestos- } \\
\text { induced } \\
\text { disease } \\
\text { development }\end{array}$ & Yes & $\begin{array}{l}\text { Mid } \\
\text { to } \\
\text { long }\end{array}$ & $\begin{array}{l}\text { Asbestos- } \\
\text { induced ascites; } \\
\text { tumour } \\
\text { dissemination } \\
\text { and invasion }\end{array}$ & $\begin{array}{l}\text { SV40 TAg phenocopies } \\
\text { p16 loss leading to high } \\
\text { incidence ( } 85-100 \%) \text { of } \\
\text { mesothelioma after } \\
\text { asbestos exposure. Little to } \\
\text { no spontaneous non- } \\
\text { mesothelioma tumours in } \\
\text { absence or presence of } \\
\text { asbestos }\end{array}$ \\
\hline
\end{tabular}

\subsection{Asbestos Exposure Models}

Using animal models to study human cancer is a widely accepted strategy that can yield answers that would not otherwise be achievable. Mesothelioma has been reported in many different animals including rodents, dogs, horses, goats, and even tigers, indicating that all mammals with pleura or peritonea are susceptible to environmental asbestos exposure (Cleo Robinson et al. 2014). 
Disease pathology stems from inhalation of long, thin asbestos fibres $(3 \mu \mathrm{m}-5 \mu \mathrm{m}$, aspect ratio $>1: 3$ ) that penetrate deep into the lung and enter the pleural space. Subsequently, a continuous inflammatory cycle of pleural irritation, DNA damage, and repair leads to mutations in mesothelial cells leading to the onset of disease. Inflammatory cytokines, including transforming growth factor- $\beta$, (TGF- $\beta$ ), plateletderived growth factor (PDGF), and vascular endothelial growth factor (VEGF), promote proliferation and angiogenesis. Phagocytosis of asbestos fibres leads to release of oxygen free radicals inducing DNA mutations, and fibre penetration of mesothelial cells interferes with mitosis. Not all individuals exposed to asbestos develop mesothelioma, suggesting host genetics may predispose some individuals to disease. Rodents, particularly mice, from different genetic backgrounds have been exposed to asbestos fibres and monitored for development of mesothelioma. Strikingly, asbestos-induced mesothelioma in mice recapitulates the human disease with regard to disease latency, growth of tumour on the mesothelium, histopathology, and chromosomal abnormalities (see Sect. 2.5 below). Many murine cell lines have since been developed from asbestos-exposed mice (Table 18.1) and have contributed significantly to our current understanding of mesothelioma biology.

\subsection{Inhalation Models}

Although inhalation studies are more representative of human exposure, their use is limited by a number of factors. Firstly, it is often difficult to regulate the number of asbestos fibres inhaled. Additionally, there is a high asbestos exposure risk to research staff and the immediate study environment. As such, inhalation studies often require specialised equipment and facilities at a cost that is often prohibitive to many research labs. Conversely, instillation of asbestos fibres via intraperitoneal (i.p.), intrapleural (i.pl), or intratracheal (i.tr) injection is more common as it is costeffective and easily performed with minimal training. Both models are equally important, and it is the hypothesis being tested that should dictate which type of model is ultimately used. When investigating the potential carcinogenicity of airborne particles on human health, an inhalation study is warranted. However, when investigating biological processes that occur once disease is induced, injection models are no less useful; how the disease is induced is not the primary concern, but what happens biologically afterwards is.

\subsection{Injection Models}

Following exposure of mice to asbestos fibres (crocidolite) via intraperitoneal injection, tumours resembling mesothelioma develop in the peritoneal cavity after 24 weeks in a29/Sv mice and C57BL/6 mice, 29 weeks in BALB/c mice, and 56 weeks in CBA mice (Davis et al. 1992). These models closely resemble the onset of human disease in terms of disease incidence (20-30\% of exposed mice) and histological and morphological features, with the notable exception that unlike human 
mesothelioma, most mouse-derived mesotheliomas are sarcomatoid, with very little epithelioid or biphasic subtypes observed (Robinson et al. 2006). Nonetheless, these models have significantly aided our understanding of the mechanisms leading to onset of mesothelioma. Although many mouse exposure models recapitulate human mesothelioma, the low disease incidence (20-30\% of exposed mice), and long latency period lag time to disease onset, is prolonged (0.5-2 years); asbestos exposure models are therefore inappropriate for many investigations such as molecular tumourigenesis and drug testing.

\subsection{Xenograft Models}

Xenograft models of mesothelioma involve the transplantation of human solid tumours or tumour cell lines into mice and are useful for investigating drug toxicity and the molecular mechanisms of tumour growth.

Xenograft models most commonly implant human mesothelioma cell lines into mice that are immune-compromised (i.e. lack an intact immune system) in order to avoid a foreign tissue response. These include mice strains such as the hairless 'nude' mouse (lack T cells), severe combined immunodeficient (SCID) mice (lack T and B cells), and recombination-activating gene (RAG) knockout mice (lack adaptive immune cells) and are often used for drug targeting of oncogenic pathways.

Other xenograft models transplant intact tumour pieces into immunecompromised mice. The advantage of these models is that the structure and integrity of the tumour is maintained, in particular the stromal compartment. Accordingly, the biological and clinical behaviour of tumour growth in the mice seems to correlate well with that observed in patients. A major disadvantage of xenograft models is that the lack of an intact immune system impacts on both tumour growth parameters and/or drug treatment response. Therefore, whilst xenograft models provide a valuable tool for assessment of targeted drug treatment of oncogenic pathways (Cleo Robinson et al. 2014), they are not suitable for investigation of immune-based treatments, such as chemoimmunotherapy.

\subsection{Subcutaneous Models}

Various murine tumour models have been developed in which tumour cells are injected directly under the skin where they develop as subcutaneous solid tumours. The advantage of these models is the visualisation of tumour growth and response to therapy. Additionally, tumours develop in the context of vasculature, connective, and lymphatic tissues allowing drug metabolism in situ to be assessed with consideration of drug pharmacokinetics, tumour accessibility, tumour biology, and the contribution of the immune system.

Mesothelioma tumours grown subcutaneously retain many morphological features of disease and can be validated by histology. The tumour size is easily measured and therefore response to drug treatment is easily assessed over time. As 
tumour growth is rapid in these models, they provide a relatively high throughput mouse model for the assessment of novel therapeutics.

The disadvantage of the subcutaneous model is that tumours develop at an anatomically irrelevant site and that rapid tumour growth may preclude normal stromal development or limit the efficacy of anti-tumour immune responses. As such, there can be significant differences in treatment responses between subcutaneous and orthotopic tumour models. In addition, the majority of murinederived mesotheliomas used in subcutaneous models display the sarcomatoid phenotype and not the epithelioid phenotype that is more common in human mesothelioma. Therefore, the suitability of the subcutaneous mouse tumours model has been questioned for relevance in the disease setting. Despite this, many therapies that are currently in the clinic for many cancer types, including chemotherapy and immunotherapy, were developed using subcutaneous mouse models (Cleo Robinson et al. 2014).

The benefits of the subcutaneous model lie in the simplicity of the method, the ability to monitor tumour growth over time, and the presence of an immune cell response to tumour growth. Some of the issues regarding translation of findings in these solid tumour models are addressed by testing treatment in a number of different subcutaneous mesothelioma models, to confirm efficacy of treatment interventions.

\subsection{Orthotopic Models}

Orthotopic models have been developed for pleural and intraperitoneal mesothelioma. These models represent a more human-like disease model, since tumours develop in an anatomically relevant site and are often more invasive relative to subcutaneous tumour models.

Orthotopic mesothelioma models mimic human disease closely, in that tumour cells grow along the serosal surfaces, form nodules in the peritoneum, develop metastases, and in some cases form ascitic fluid. Importantly, tumours develop in the context of the host tissue, and tumour growth is subject to relevant host factors such as the immune system, vasculature, metabolites, and microenvironment.

A high level of technical expertise is required for the intrapleural orthotopic model due to risk associated with intrapleural injections such as hemothorax and pneumothorax (Cleo Robinson et al. 2014). For this reason, intraperitoneal models of mesothelioma are more commonly used as they conserve the same biological features of disease as the intrapleural model but are easier to perform, even by less skilled personnel.

A potential disadvantage of the orthotopic model is the inability to directly monitor tumour growth. This can be overcome by the use of small animal imaging techniques where growth of cancer cells expressing a fluorescent reporter protein, or the luciferin gene that converts substrate to emit light, can be measured. Additionally, the development of small animal imaging platforms that mimic clinical disease detection such as PET-CT and MRI and the utilisation of radio-nucleotide tracers are becoming more readily available. 


\subsection{Genetic Predisposition Models}

Mesothelioma is a disease of genetic loss, often characterised by the deletion of the tumour suppressor genes $C D K N 2 A$, encoding the proteins $\mathrm{p} 16^{\mathrm{INK} 4 \mathrm{a}}$ and $\mathrm{p} 14^{\mathrm{Arf}}$ (p19 ${ }^{\mathrm{Arf}}$ in mice), $N F 2, B A P 1$, and to a lesser extent $p 53$. Accordingly, mouse models have been developed in which these genes, either individually or in combination, are no longer expressed, i.e. the genes have been 'knocked out' (KO models). Mice in which a single copy of $N F 2$ or $p 53$ have been deleted (heterozygous $\mathrm{KO}$ mice) display increased incidence of mesothelioma (up to $80 \%$ of mice) and a shorter disease latency following asbestos exposure. Importantly, both NF2 and $p 53$ heterozygous mice develop other types of highly metastatic lesions (Cleo Robinson et al. 2014) and other spontaneous cancers, such as lymphomas, sarcomas, and adenocarcinomas. It is also notable that these mouse models don't require exposure to asbestos for disease development and become complicated by spontaneous occurrence of many non-mesothelioma tumours. Whilst a disadvantage of these models is the induction of mesothelioma in the absence of asbestos exposure, they have still been instrumental in elucidating the molecular mechanisms that lead to mesothelioma following asbestos exposure.

\subsection{MexTAg Mice}

Our lab developed the MexTAg transgenic mouse model of mesothelioma in which mesothelial cells have been engineered to express the oncogenic SV40 virus large T antigen (SV40 TAg) (Robinson et al. 2006). Whilst SV40 does not play a causative role in human mesothelioma, we utilise the oncogenic potential of TAg as a disease accelerator, producing a mouse model in which mesothelioma development is predictable, uniform, and reproducible, but only after asbestos exposure. MexTAg mice have higher disease incidence (up to 100\%), develop mesothelioma with similar pathology, and show comparable treatment responses to human mesothelioma (Robinson et al. 2006, 2011,). Importantly, MexTAg mice are less likely to develop unrelated tumours compared to wild-type mice or the heterozygous or conditional mesothelioma knockout mouse models mentioned above. Expression analysis comparing MexTAg and wild-type mesotheliomas with their counterpart normal mesothelial cells demonstrates highly homologous gene expression profiles that suggest the TAg transgene does not affect the overall mechanism of mesothelioma development, but rather it phenocopies p16 loss - leading to increased disease incidence in these mice after asbestos exposure (Robinson et al. 2015). Thus, the MexTAg model is a functional equivalent of the deletion of tumour suppressor genes such as $C D K N 2 A$ $\left(p 16^{I N K 4 a} / p 14^{A r f}\right), N F 2, B A P 1$, or $p 53$ that characterise human mesothelioma.

The reproducibility and high incidence of disease in asbestos-exposed MexTAg mice make this model ideal for disease prevention studies as well as assessing the potential carcinogenicity of minerals and materials that share asbestos-like characteristics such as long carbon nanotubes and non-asbestiform elongated mineral particles (Table 18.2). 


\section{Conventional Therapies}

\subsection{Surgery}

The benefits of surgery in pleural mesothelioma are hotly debated (Opitz and Weder 2017). Factors taken into consideration when recommending patients for surgery include disease stage and histology. Patients with less bulky tumours are often treated with pleurectomy/decortication $(\mathrm{P} / \mathrm{D})$ surgery, whilst high-risk patients undergo the more radical extrapleural pneumonectomy (EPP). The IASLC database, however, indicates an OS benefit of 40 months for EPP and 23 months after P/D. This is further complicated by 30-day mortality rates at 2-5\% after EPP surgery. This is unsurprising as many patients selected for EPP are already high risk, and the procedure has a relative risk for technical complications including haemorrhage, empyema, failure at reconstruction of the diaphragms or pericardium, atrial fibrillation, and acute respiratory distress syndrome (ARDS).

Given the low frequency of MM patients suitable for surgical resection, some centres are now trialing neoadjuvant chemotherapy or radiotherapy to patients (see below).

\subsection{Chemotherapy}

Current studies indicate that neoadjuvant chemotherapy prior to surgery is feasible; however it is yet to be determined if there is an associated survival benefit.

Historically, chemotherapy has been considered immunosuppressive via depletion of immune cells sensitive to treatment. The action of chemotherapy was thought to occur primarily by inhibition of tumour cell division. More recently there has been overwhelming evidence of the positive effects of chemotherapy on anti-tumour immune responses. These immune benefits include stimulation of immunogenic tumour cell death, tumour antigen presentation, depletion of suppressive cells, and stimulation of anti-tumour $\mathrm{T}$ cell immune responses. Types of chemotherapy for use in mesothelioma, their target, and immunomodulatory properties are listed in Table 18.3.

\subsubsection{Immunogenic Tumour Cell Death}

Under normal physiological conditions, cells die in a manner that does not provoke an immune response (i.e. non-immunogenic), avoiding immune reactivity to selfproteins. Some chemotherapies, however, are able to kill cells in an immunogenic manner. Here, chemotherapy may promote tumour antigen uptake by dendritic cells whilst inducing activation of those DC through release of alarmin proteins. Additionally, chemotherapy can induce recruitment and maturation of dendritic cells that ultimately induces an anti-tumour immune response (Aston et al. 2014).

\subsubsection{Dendritic Cell Cross-Presentation}

Mature dendritic cells can uptake and display tumour-derived peptides on MHC class I molecules to CD8 $\mathrm{T}$ cells in a process known as cross-presentation. 


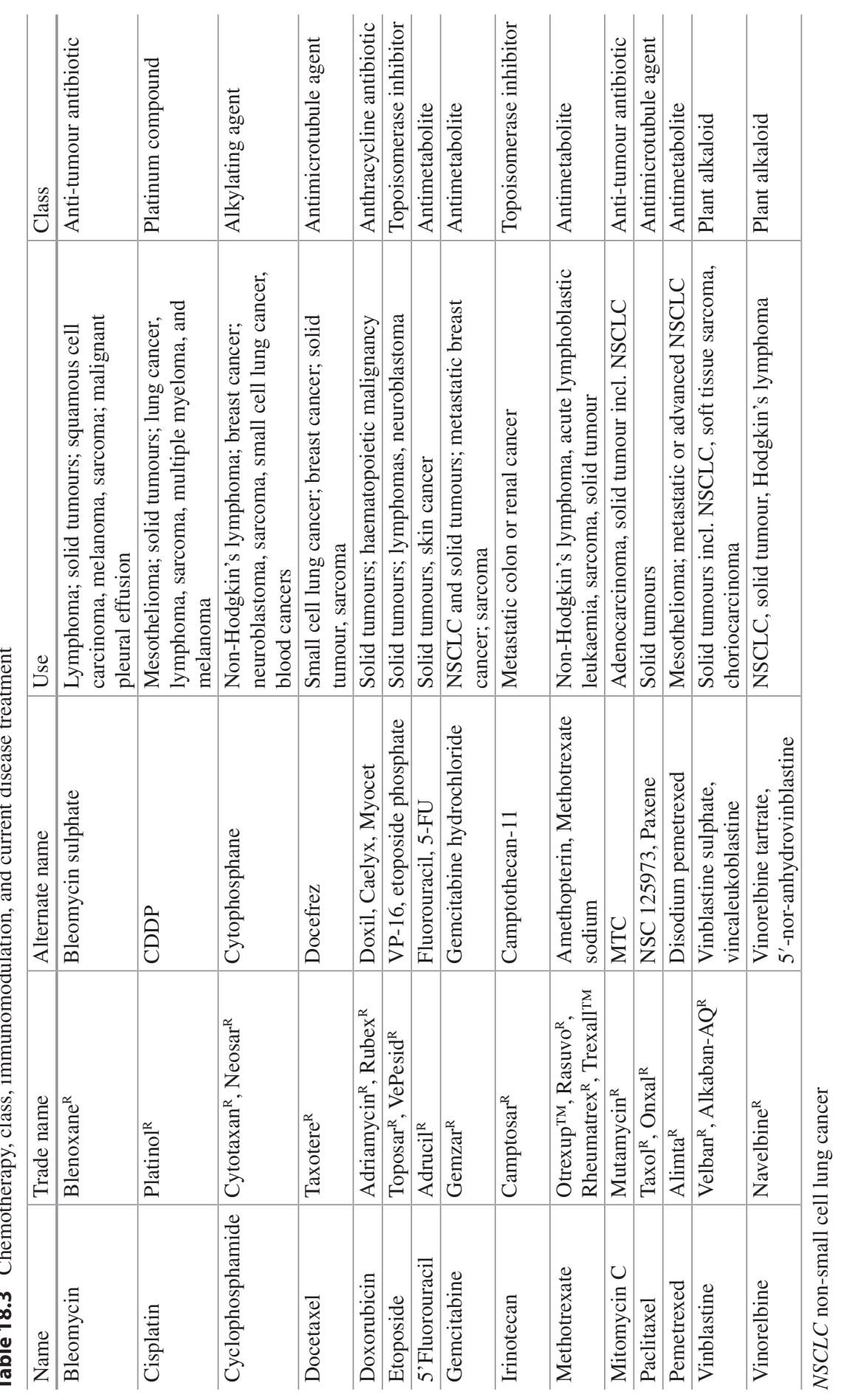


Gemcitabine, a chemotherapy used in thoracic cancer, enhances dendritic cell crosspresentation, leading to activation of tumour-specific CD8 T cells in murine mesothelioma (Nowak et al. 2003a). Chemo-modulation of dendritic cells has also been demonstrated with low-dose paclitaxel, doxorubicin, mitomycin C, methotrexate, and vincristine (Aston et al. 2014).

\subsubsection{Depletion of Immune Suppressive Cells}

Tumour cells secrete IL-10 and TGF $\beta$ to enhance the suppressive immune function of Treg cells and myeloid-derived suppressor cells (MDSCs). In a murine mesothelioma model, tumour eradication after low-dose cyclophosphamide is achieved, in part, due to depletion of suppressive Treg cells (Aston et al. 2014). Other chemotherapeutics such as gemcitabine and 5'fluorouracil (5'FU) deplete MDSCs and augment lung tumour regression (Aston et al. 2014). Conversely, gemcitabine and 5'FU chemotherapy may blunt the anti-tumour response by activating the NOD-like receptor protein (NLRP) inflammasome and release of the immunosuppressive cytokine IL1- $\beta$. This example highlights the need for careful delineation of mechanism of action of chemotherapeutic drugs to better inform decisions associated with combination therapy.

\subsubsection{Enhancing Cytotoxic T Lymphocyte Activity}

Cytotoxic T lymphocytes (CTLs) secrete the protease granzyme B to kill tumour cells. Paclitaxel, cisplatin, and doxorubicin increase tumour cell permeability, sensitising tumour cells to CTL killing (Ramakrishnan et al. 2010), whilst other platinum-based chemotherapies promote anti-tumour immunity by enhancing DC-mediated CTL activation (Lesterhuis et al. 2011). Additionally, in vitro studies using cisplatin have shown downregulation of T cell inhibitory ligands PD-L1 and PD-L2 on both tumour cells and DCs, thus enhancing T cell recognition in vitro.

\subsection{Radiotherapy}

Clinical MM has traditionally been considered radiotherapy resistant, despite in vitro studies showing mesothelioma cell lines to be sensitive to doses as little as 2 grays (Gy). Epithelial mesothelioma subtypes appear more susceptible to irradiation than sarcomatoid cell lines (Sharabi et al. 2015). More recently the development of new radiation therapy techniques such as intensity-modulated radiation therapy (IMRT), which allows delivery of high-dose radiotherapy to the hemithorax, has shown efficacy. In clinical trials IMRT after EPP led to a patient survival of 23.9-39.4 months (Perrot et al. 2017). Accordingly, IMRT adjuvant therapy has been introduced after P/D and EPP. Further studies are indicating that IMRT is a feasible option prior to surgery and may increase survival before EPP, as in the SMART protocol (Cho et al. 2014). Radiotherapy is also prophylactically used for biopsy tract metastases, which occur in around $20 \%$ of patients, but this is controversial and studies to date have been largely negative. A large randomised trial designed to definitively answer whether this procedure is beneficial is currently in progress (Bayman et al. 2016). 


\section{$4 \quad$ Emerging Therapies}

Cutting-edge research into MM targets the immune system, oncogenes and their signaling pathways, early disease detection by biomarker identification, as well as novel studies including drug repositioning and combination treatment modalities. These topics are discussed below.

\subsection{Immunotherapy}

There is a strong immunological rationale for using immunotherapy to treat mesothelioma. Tumour biopsies with high levels of $\mathrm{CD}^{+}$tumour-infiltrating lymphocytes (TILs) are positively correlated with tumour regression and improved survival. However, despite the infiltration of T effector (Teff) cells, tumours can escape elimination by the immune system through the involvement of $\mathrm{T}$ cell inhibitory molecules (CLTA-4 or PD-1, PD-L2), or the development of a suppressive tumour microenvironment (TME), characterised by high levels of Treg cells (Fisher et al. 2017) and suppressive cytokines such as TGF- $\beta$ and IL-10.

New strategies for the treatment of cancer include therapies that target the immune system. The recognition of tumour by the immune system occurs in several stages (Figs. 18.1 and 18.2). Initially the immune system recognises tumour cells via direct presentation of tumour antigens in MHCI molecules on the tumour itself or via presentation of antigen on dendritic cells leading to activation of CD8 T cells in the lymph nodes. The activated CD8 T cells then traffic to the tumour site and are further presented with tumour antigen, via tumour cells or antigen-presenting cells. Following antigen exposure CD8 T cells then produce granzyme B and perforin in an anti-tumour cytotoxic response. However, at each stage of the immune process, there are checks in place to suppress or control the anti-tumour response. These checks to inhibit the immune response can be provided by tumour cells, antigenpresenting cells, immunosuppressive cells (i.e. Treg, MDSC), and/or the cytokine milieu.

Current emerging immunotherapy for treatment of mesothelioma includes immune checkpoint blockade (ICPB), CAR T cell therapy, T regulatory cell modulation, and neoantigen vaccination.

\subsubsection{Immune Checkpoint Blockade}

One of the most exciting recent advances in cancer therapy is immune checkpoint blockade (ICPB) where the therapy is focused on modulating the immune system rather than the tumour. Upon activation, immune cells express a variety of costimulatory and co-inhibitory molecules: molecular 'checkpoints' that dictate the amplitude and duration of the immune response (Steven et al. 2016). Inhibitory checkpoint molecules, such as cytotoxic T lymphocyte antigen (CTLA-4) and programmed cell death protein 1 (PD-1), are expressed on immune cells in order to protect host cells from prolonged inflammation and/or autoimmunity, acting as an 'off' signal for the immune system. 


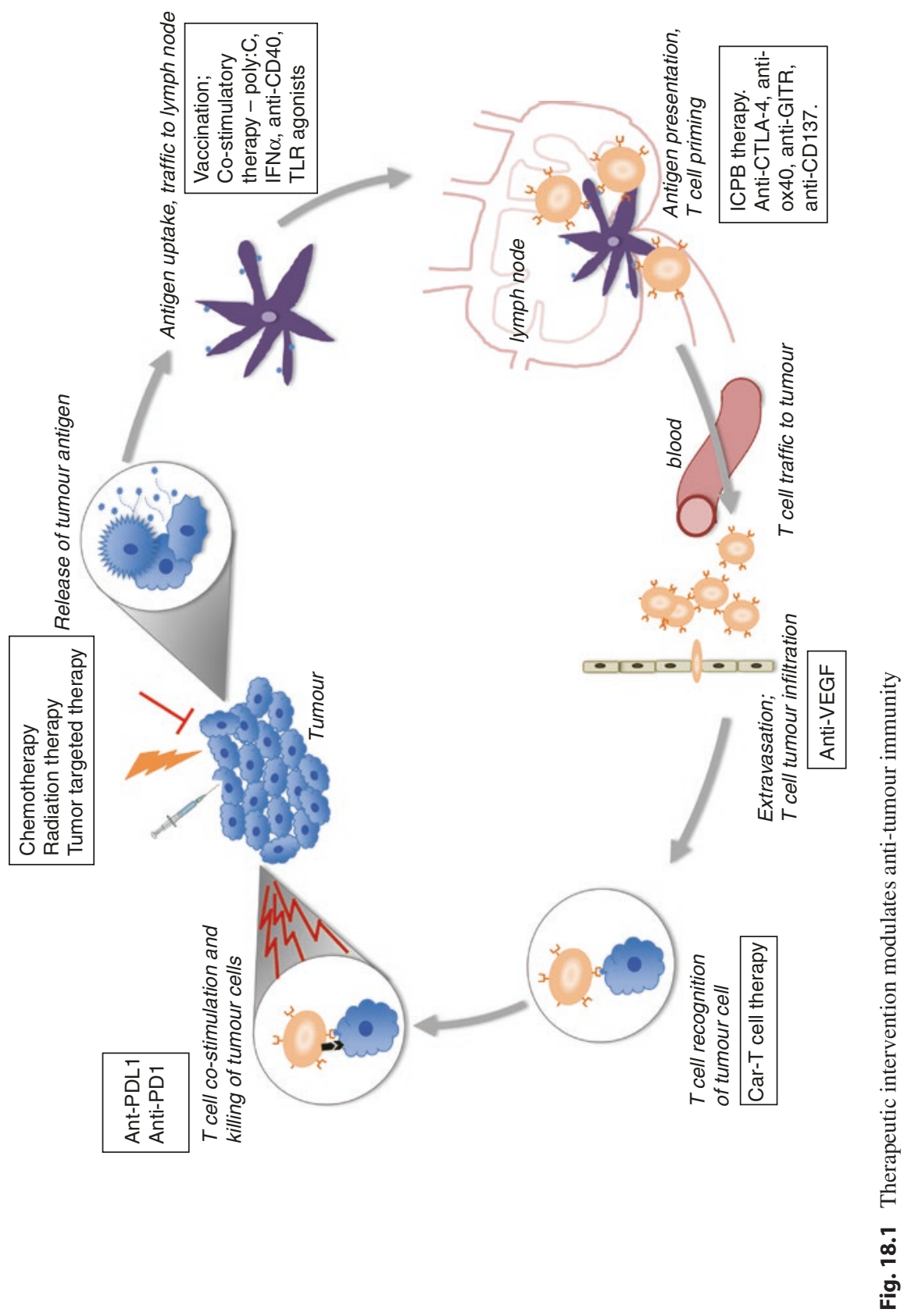




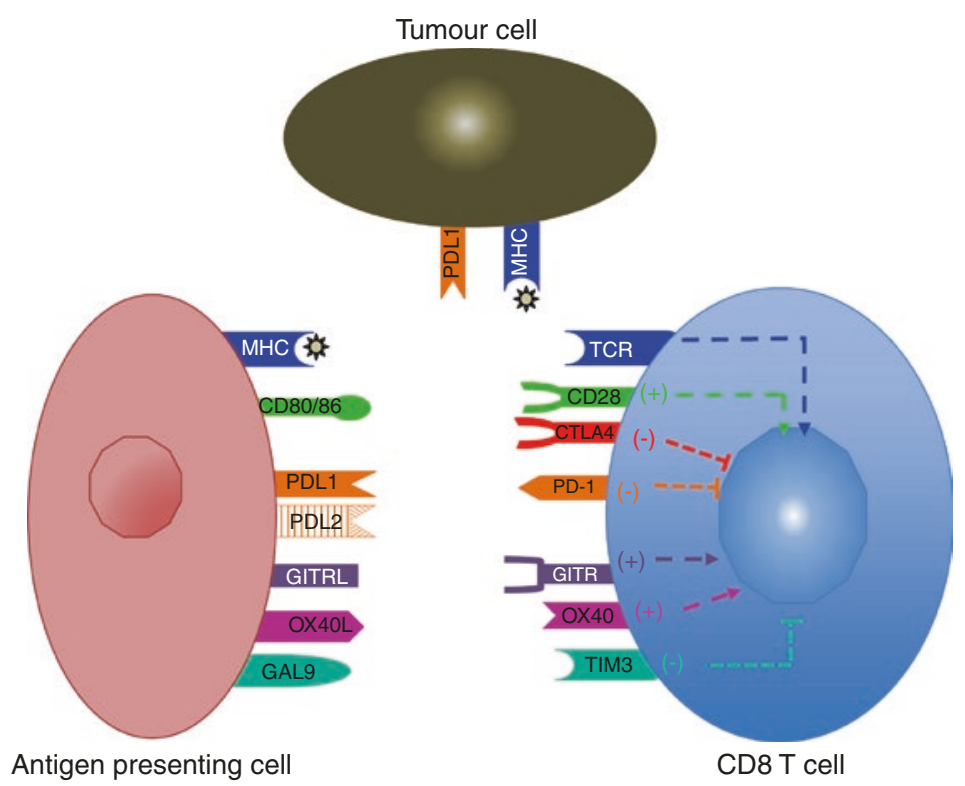

Fig. 18.2 Immune checkpoint receptors and their action on $\mathrm{T}$ cell activation

CTLA-4 opposes the co-stimulatory signals generated by CD28 during T cell activation, by disrupting binding of CD28 to its cognate ligands CD80/CD86. Binding of CTLA-4 to CD80/CD86 promotes Teff cell inhibition. In addition, CTLA-4 is constitutively expressed on immunosuppressive Treg cells. Targeted antibodies against CTLA-4 release the block on T cell activation and deplete T regulatory cells. In murine mesothelioma models, blockade of CTLA-4 using antiCTLA-4 monoclonal antibodies delayed tumour growth.

PD-1 functions primarily in peripheral tissue to inhibit $\mathrm{T}$ cell activation, by binding to its cognate ligands programmed death ligand-1 (PD-L1) and programmed death ligand 2 (PD-L2), expressed on tumour and dendritic cells, respectively. Similar to CTLA-4, ligation of PD-1 inhibits T cell proliferation and secretion of effector cytokines. Limited preclinical information on PD-1 blockade is published in mesothelioma, but in combination with adjuvant therapies in other preclinical models, tumour growth is delayed.

Alternative new immune checkpoint targets, which include inhibitory receptor T cell immunoglobulin 3 (TIM-3), and stimulatory receptors OX40 and glucocorticoid-induced tumour necrosis factor receptor (TNFR)-related protein (GITR), are in the early stages of clinical development and may be alternative targets for ICPB therapy in mesothelioma. TIM-3 is an inhibitory molecule that mediates immune tolerance and along with PD-1 expression marks a dysfunctional population of CD8 T cells. Stimulatory OX40 and GITR promote the survival and proliferation of Teff cells and reduce the activity of immunosuppressive Treg cells. 
Although ICPB shows promise for cancer therapy, only a small proportion of mesothelioma patients experience a durable response. Combined with the limited preclinical data on ICPB in mesothelioma, there is a clear need for increased preclinical research into the use of novel immune checkpoints or combination therapies.

\subsubsection{CAR T Cell Therapy}

$\mathrm{T}$ cell activation is a two-step process in which naïve $\mathrm{T}$ cells, via the $\mathrm{T}$ cell receptor (TCR), first recognise their cognate antigen in the context of a major histocompatibility complex (MHC). Once the TCR binds the MHC-antigen complex (signal 1), additional co-stimulatory signals, provided by $\mathrm{CD} 3 \zeta$ and $\mathrm{CD} 28$ binding to CD80/CD86 (signal 2), are required to promote $\mathrm{T}$ cell activation. $\mathrm{T}$ cells that receive signal 1 , but not signal 2, are considered anergic; they remain inactive and are non-functional.

A chimeric antigen receptor (CAR) combines the two-step activation process into a single activating receptor. A CAR incorporates the extracellular domain of the TCR specific to the tumour antigen with the intracellular activating domain of the $\mathrm{CD} 3 \zeta$ cell receptor. To increase $\mathrm{T}$ cell activation in vivo, second- and third-generation CARs have been developed by fusing the $\mathrm{CD} 3 \zeta$-activating domain with additional co-stimulatory intracellular domains such as CD28 or 4-1BB (Zeltsman et al. 2017). Autologous $\mathrm{T}$ cells can then be transduced with a CAR construct to generate CAR $\mathrm{T}$ cells that can be fully activated upon binding to their cognate ligand.

To be useful as a cancer therapy, CAR T cells must recognise tumour-specific antigens. Initial studies assessing the efficacy of CAR T cells that recognise mesothelin, a protein that is overexpressed by mesothelioma but has low-level expression on normal mesothelial cells, indicated that although there was no off-target toxicity of mesothelinspecific CAR T cell therapy, there was no consistent clinical response (NCT02414269, NCT01583686, NCT02580747, NCT02159716, and NCT 01355965).

Nonetheless, preclinical studies have demonstrated the potential for effective CAR $\mathrm{T}$ cell therapy for mesothelioma. In an intrapleural mesothelioma mouse model, treatment with mesothelin-specific CAR T cells injected into the peritoneum induced potent, long-lasting anti-tumour immunity (Zeltsman et al. 2017).

Other targets for CAR T cells include components of the tumour-associated stroma, including fibroblast-activating protein (FAP) and vascular endothelial growth factor receptor 2 (VEGFR2). Preclinical studies demonstrate murine FAPspecific CAR $\mathrm{T}$ cells have efficacy in mice bearing subcutaneous mesothelioma with minimal toxicity (Zeltsman et al. 2017). A phase I clinical trial of human FAPspecific CAR $\mathrm{T}$ cells via intrapleural administration in mesothelioma patient has commenced (NCT01722149).

Alternative CAR T strategies in development for mesothelioma focus on coexpression of ErbB family members (EGFR, HER2, ErbB3, and ErbB4) in conjunction with chimeric cytokines receptors, which serve to promote IL-2-/IL-15-driven clonal expansion of CAR T cells in vivo (Zeltsman et al. 2017). Other candidates of interest for CAR T cell therapy include the oncofoetal cell surface glycoprotein (5 T4) and surface proteoglycan chondroitin sulphate proteoglycan 4 (CSPG4), which are known to be highly overexpressed in mesothelioma cell lines and biopsies. 
Current strategies in murine models to enhance CAR T cell therapy are targeting suppression of soluble inhibitory signals (adenosine, TGF $\beta$ and $\mathrm{PGE}_{2}$ ) and evasion of checkpoint inhibitors (such as PD-1) by addition of modified cell surface receptors to subvert their action.

\subsubsection{Regulatory T Cell Modulation}

Treg cells maintain peripheral tolerance and limit autoimmunity via crosstalk with antigen-presenting cells (APC) and Teff cells. In preclinical cancer models, depletion of Treg cells correlates with enhanced anti-tumour immunity. Indeed, we have shown that mesothelioma bearing BALB/c.FOXP3.dtr mice treated with diphtheria toxin (DTX) to systemically deplete Treg cells in a transient, dose dependent manner, leads to tumour clearance in $20-80 \%$ of mice (Fisher et al. 2017). Low dose-DTX mediated removal of Treg cells also enhanced the efficacy of tumour-specific vaccination. A major limitation to translating these data into the clinic is the ability to specifically target Treg cells in patients as there are no known reagents that specifically target Treg cells without affecting other Teff cell populations. We (Fear et al. 2018) and others (Marabelle et al. 2013) have shown that ICPB targeting OX40 and CTLA-4 (both highly expressed on Treg) has been successful in inducing tumour regression in mice, presumably by Treg depletion (Marabelle et al. 2013). However, Tregspecific immunotherapies have yet to be validated in the clinical setting.

\subsubsection{Neoantigens and Vaccination}

The host immune system is capable of recognising and targeting tumour cells. Numerous sources of tumour-associated antigens (TAAs) or neoantigens arise due to mutation of oncogenes and suppressor genes, oncofoetal proteins, oncogenic viruses, or overexpression of proteins. In order to stimulate an anti-tumour immune response, neoantigens must be present to T cells in the context of MHC molecules. To identify mutations, patient tumour samples are sequenced using next-generation sequencing (NGS) technology for aberrations compared to their normal cellular DNA. Mutation expression is confirmed by RNAseq, and MHC binding potential determine in silico. Finally, neoantigen peptide is compared to the normal (wild type; WT) peptide to identify tumour-specific T cell reactivity (Creaney et al. 2015).

The ability to identify tumour-specific neoantigens via NGS platforms has reinvigorated anti-cancer vaccination strategies. Patients can potentially be vaccinated with their own tumour-specific neoantigens (Chee et al. 2017), in a form of personalised medicine. Current vaccination strategies combine chemotherapy and/or immunotherapy treatment with peptide to stimulate anti-tumour immunity (Bakker et al. 2017).

\subsection{Targeting Molecular Signaling Pathways, Oncogenes, and Tumour Suppressor Genes}

\subsubsection{Kinase Inhibitors}

Dysregulation of cell surface receptor expression has been reported in mesothelioma. This includes EGFR overexpression; differential expression of PDGF subtypes; VEGF and VEGF-C constitutive activation of RTKs; and c-MET receptor autocrine 
loop/overexpression. These mutations induce downstream changes in a multitude of signaling pathways including Hippo, mTOR, MAPK, TP53, and PI3K/Akt.

EGF receptor pathway, PDGFR receptor pathway, VEGF pathway, and Notch receptor signal the phosphatidylinositol 3-kinase (PI3K/AKT) pathway and are frequently activated in mesothelioma (Ramos-Nino et al. 2006; Thellung et al. 2016). Activation of AKT triggers anti-apoptotic mechanisms, enhances NF-kB transcription, modulates angiogenesis, increases telomerase activity, potentiates tumour invasion, and inhibits cell cycle arrest (Ramos-Nino et al. 2006). Recent combination inhibitors against the PI3K and mTOR pathways mutual downstream signaling pathways have proven more effective than individual pathway targeting in human cell lines, and xenograft mouse models.

FAK, a non-receptor tyrosine kinase, belonging to signal pathways downstream of growth factor receptors and integrin-mediated cell adhesion (Thellung et al. 2016), is also overexpressed in mesothelioma. FAK signaling enhances cell survival, proliferation, migration, and tissue invasion. FAK-targeting pharmacological agents are currently being tested in the preclinical setting (Shapiro et al. 2014). Application of focal adhesion kinase (FAK) inhibitor, defactinib, demonstrated efficacy in NF-2-deficient tumours in vitro; however clinical trials were halted due to a lack of efficacy.

The c-MET receptor tyrosine kinase is often overexpressed in mesothelioma. Binding of the ligand receptor, hepatocyte growth factor (HGF), for this protooncogene enhanced cell proliferation, motility, and invasion, whilst promoting tumourigenesis and metastasis (Thellung et al. 2016). Notably combinatorial treatment with PI3K and c-Met RTK inhibitors has demonstrated increased efficacy in human mesothelioma cell line culture, resulting in G2-M arrest and apoptosis. Combination therapy in mouse models was also highly synergistic, reducing mesothelioma tumour growth.

Other drugs tested in the RTK space for mesothelioma treatment include EGFR inhibitors, BCR-Abl inhibitors, thalidomide, bortezomib, and vorinostat, all of which failed to improve patient outcome. Notably in each of these studies, a subgroup of patients appeared to benefit from treatment. Current studies are therefore underway to identify biomarkers for these treatment-sensitive subgroups.

\subsubsection{Cancer Stem Cell Signaling}

Cancer stem cells are commonly considered as the progenitor of tumour initiation, progression, recurrence, and resistance to treatment. This is because cancer stem cell progeny may be killed by chemotherapy or radiotherapy, whereas cancer stem cells are resistant. This therapy resistance may be attributed to the self-renewal capability of these cells and expression of stem-like intracellular signaling pathways. Activation of these stem-like pathways in mesothelioma patients associates with poor prognosis. Stem-like intracellular signaling mechanisms under investigation in mesothelioma include growth factor receptor pathways, Wnt signaling, Notch pathways, TGF $\beta$, and Hippo and hedgehog pathway (Thellung et al. 2016).

The Wnt signaling pathway is involved in cell fate and proliferation in embryogenesis. Dysregulation of Wnt signaling by fizzled transmembrane receptors, is associated with tumourigenesis. Inhibition of Wnt signaling in mouse and human lung adenocarcinoma has been shown to inhibit tumour growth (Nusse and Clevers 2017). 


\subsubsection{Oncogenes and Tumour Suppressor Genes}

Comprehensive genomic analysis of mesothelioma samples has found a landscape of mutated or altered tumour suppressor genes including BAP1, NF2, TP53, SETD2, and CDKN2A (Bueno et al. 2016). As loss of function genes, these cannot be targeted, and therefore downstream signaling molecules have been identified as potential therapeutic targets.

Chromatin is composed of DNA, RNA, and proteins. Histones form the basic protein structure of chromatin, where an octamer of histone subunits forms the nucleosome. DNA is wound around these nucleosome subunits to tightly pack DNA within the cell. Decondensation of the nucleosome is required for gene expression and involves epigenetic regulation including DNA methylation, as well as histone methylation, acetylation, and phosphorylation. Tumour suppressor genes can be regulated by epigenetic changes, leading to condensation of chromatin, and loss of heterozygosity. Histone acetyl transferases and deacetylases (HDACs) control DNA methylation and chromatin condensation. Early studies indicated a role for hypermethylation of $\mathrm{CpG}$ repeats in promoter regions of tumour suppressor genes in mesothelioma cell lines expressing SV40. Latter studies provide more convincing evidence for treatment of mesothelioma with histone deacetylase inhibitors (Paik and Krug 2010).

Treatment of mesothelioma cell lines with HDAC inhibitors (HDACi) leads to apoptosis. HDAC inhibitors tested include sodium butyrate, suberoylanilide hydroxamic acid, and depsipeptide that induce apoptosis via downregulation of the anti-apoptotic protein bcl-XL. In other studies, pan-HDAC inhibitor LBH589 or valproic acid treatment of mesothelioma cell lines induced apoptosis in a caspase-dependent manner, whilst valproic acid in combination with chemotherapy has now demonstrated increased efficacy in human epithelioid mesothelioma mouse xenograft models.

Clinical trials with the HDAC inhibitors belinostat (PXD101) and vorinostat are complete, however data has not yet been released. New pre-clinical studies, however, indicate increased efficacy of HDAC inhibitors in combination with chemotherapy. Further in a phase I clinical trial of five mesothelioma patients treated with vorinostat in combination with cisplatin and pemetrexed, $60 \%$ exhibited stable disease (Paik and Krug 2010).

The entire INK4a/ARF locus is deleted in greater than $70 \%$ of human mesothelioma cell lines. The INK4A/ARF locus encodes p16INK4a and p14ARF that regulate expression of the oncogene p53 and retinoblastoma protein (pRB) pathways, leading to G1 arrest and G0 arrest/apoptosis, respectively. Adenoviral p14ARF infection of human mesothelioma cell lines led to cell cycle arrest, growth inhibition, and apoptosis (Paik and Krug 2010). Further, p14ARF gene therapy restoration of p53 activity is being investigated as a tool to enhance the efficacy of radiation and chemotherapy treatment.

\subsection{Biomarkers}

The identification of biomarkers specific to mesothelioma is a useful tool for monitoring at-risk populations for early diagnosis and tumour response to therapy (Arnold 
and Maskell 2018). A good biomarker needs to be preferentially expressed at a relatively high level on mesothelioma cells and detected with high sensitivity and specificity. An ideal biomarker would be detectable in the serum of asbestos-exposed individuals at early stages of disease, prior to radiological confirmation of disease.

Candidate mesothelioma biomarkers include mesothelin, osteopontin, fibulin-3, and vascular endothelial growth factor (VEGF). Mesothelin is highly expressed on mesothelioma cells with low-level expression on some normal tissues (Robinson and Lake 2005). In mesothelioma patients, soluble mesothelin was detected in the blood with a sensitivity of $83 \%$ and specificity of $95 \%$. As a predictive marker however, soluble mesothelin decreases to below an acceptable limit with only $75 \%$ of patients' serum positive at diagnosis, and patients with sarcomatoid phenotype have low or undetectable SM throughout disease. Importantly, after therapy decreased SM levels do correlate with surgical tumour debulking, response to therapy, or improved overall survival (Arnold and Maskell 2018).

Osteopontin (OPN) is a glycoprotein that mediates cell-cell interactions and is overexpressed on breast colon and lung malignancies. As a biomarker, OPN has low sensitivity (57\%), and moderate specificity (81\%), and therefore is not suitable for diagnostic testing. In addition OPN serial monitoring did not correlate with debulking surgery or response to chemotherapy. However, OPN has been demonstrated to have predictive potential of poor prognosis (Arnold and Maskell 2018).

Fibulin-3, thought to phosphorylate EGF, is reported in the serum of asbestosexposed populations with a sensitivity of $87 \%$ and specificity of $89 \%$ and again falls below the level required for diagnostic testing. A number of studies indicate a correlation between high fibulin-3 serum levels at diagnosis and poor prognosis. VEGF similarly is elevated in mesothelioma with insufficient accuracy for a diagnostic test with $70.6 \%$ sensitivity and $88.1 \%$ specificity (Arnold and Maskell 2018).

The future of biomarker research is focused on identification of new biomarkers, validation of existing biomarkers or panels of biomarkers, and targeted biomarker research.

MicroRNA (miRNA) signatures have been identified in mesothelioma patients. These miRNA target mRNA after transcription and modulate translation. miRNAs are small non-coding RNA molecules that function as oncogenes or target tumour suppressor genes and are implicated in cell transformation. Identified markers of prognostic value include hsa-miR-29c*. In comparative studies on normal mesothelial and mesothelioma cells, there is upregulation of miR17-92 cluster. Other studies indicate downregulation of miR-126 in asbestos-exposed and mesothelioma patients; however $75 \%$ sensitivity and 54\% specificity are too poor for diagnostic testing.

Hyaluronic acid is found in the blood and pleural effusions of patients with mesothelioma. New technology has allowed more accurate testing for hyaluronic acid. Recent studies indicate increased predictive value for combination testing of pleural fluid for hyaluronic acid and soluble mesothelin (Creaney et al. 2013) in diagnostic testing of mesothelioma. However the exact pathophysiology of these findings is uncertain and future optimisation is required.

Other studies have combined plasma mesothelin and microRNA miR-103a-3p detection. This sensitivity and specificity of mesothelioma patient testing increased from $74 \%$ and $89 \%$ to $95 \%$ and $81 \%$, for mesothelin alone or combination testing, 
respectively. More recently studies show increased diagnostic significance for changes in the combination levels for miR-26, methylated thrombomodulin, and soluble mesothelin that are superior to current available screening tests (Santarelli et al. 2015).

New microRNA studies in mesothelioma are investigating the epigenetic methylation and inactivation of miRNA34/b/c. Active expression of miRNA34/b/c induces cell cycle arrest and inhibition of cell migration and invasion in both primary mesothelial cells and mesothelium cell lines. Further, xenograft mesothelioma studies have shown reduced tumour growth in adenovirus miRNA-34b/c-infected tumour cells. Other microRNAs such as oncogenic miR17 and miRNA-1 have also been targeted for modulation or re-expression to induce apoptosis in mesothelioma cells.

Finally, mesothelin has been investigated as an anti-tumour target using antibody therapy including anti-mesothelin immunotoxin SS1P and amatuximab (MORAb-009) or more recently the combination antibody-drug conjugate anetumab ravtansine (Thellung et al. 2016).

\subsection{Novel Studies}

\subsubsection{Drug Repositioning}

In the new technology age, many drugs are now being utilised off-target for disease treatment. This is possible as new DNA, RNA, and protein analysis can identify aberrant pathways in cancer cells, and then existing drugs can be used to interrupt these pathways and inhibit tumour cell growth (Thellung et al. 2016).

Metformin, used in type 2 diabetes, reduces tumour cell growth in many cancers. Whilst not tested in mesothelioma patients, mesothelioma cell treated with metformin had reduced intercellular communication a common structural feature in mesothelioma.

Disulfiram, a drug used to treat chronic alcoholism, has shown anti-tumour activity in humans, with suppressed proliferation in mesothelioma cells. Zoledronic acid, a nitrogen bisphosphonate, similarly arrests mesothelioma cells in S-phase. Estrogen receptor $\mathrm{b}(\mathrm{ERb})$ has been identified as tumour suppressor in mesothelioma. Treatment of mesothelioma in vitro and in vivo with the agonist KB9520 also had efficacy alone and increased sensitivity to cisplatin.

NSAIDs in the form of aspirin or Cox-2 selective inhibitors (celecoxib) have been investigated as a preventative for mesothelioma in that they may alleviate chronic inflammation after asbestos exposure. In mice there was significantly prolonged disease latency, but no change in rate of development or survival.

Itraconazole, an antifungal drug, has anti-tumour activity in mesothelioma at the level of angiogenesis and suppression of Hedgehog $(\mathrm{Hh})$ signal transduction.

\subsubsection{Viral and Gene Therapy}

Viral therapy has been investigated as a therapy for mesothelioma (Pease and Kratzke 2017), with some success for non-replicating, conditional-replicating, and replication-competent viruses in preclinical models of mesothelioma. 
Replication incompetent adenoviral vector expressing HSV-thymidine kinase suicide gene (Ad.HSV $t k$ ) rendered tumour cells susceptible to ganciclovir treatment both in vitro and in animal models (Pease and Kratzke 2017). Other adenovirus vectors expressing IFN-gamma also induced effective anti-tumour immunity, particularly with the addition of the expression of the co-stimulatory molecule CD40L (Friedlander et al. 2003).

In conditionally replicating adenoviruses, expression of viral protein is under the control of tumour-specific promoters. Accordingly, viral protein expression is limited to tumour cells and induced oncolysis in human mesothelioma cell lines.

Vaccinia viruses have been designed to infect tumour cells and stimulate and anti-tumour immune response. The replication-competent GLV-1 h68 virus successfully replicated and lysed multiple human mesothelioma cell lines in vitro. Importantly, this GLV-1 h68 virus reduced tumour burden and increases survival after intrapleural delivery in a murine model of mesothelioma (Belin et al. 2013).

\subsubsection{Combination Treatment Modalities}

The need for more effective treatment of mesothelioma and other solid tumours has led to exploration of combination modality treatments with ICPB, chemotherapy, radiation therapy, RTKs, anti-angiogenic drugs, and/or cytokine therapy.

\section{Chemotherapy and ICPB}

ICPB has met with limited success for mesothelioma, and new strategies are investigating combination treatment modalities for chemotherapy and ICPB. This is largely based on the somewhat recent findings of the immunomodulatory capacity of chemotherapy that may synergise with ICPB treatment.

The first study to demonstrate efficacy of combination chemotherapy and immunotherapy against mesothelioma was gemcitabine and anti-CD40 in a murine solid tumour model (Nowak et al. 2003b). More recent studies have combined anti-CTLA4 with the chemotherapies cisplatin, paclitaxel, etoposide, ixabepilone, and melphalan to demonstrate an additive effect of combination therapy (Aston et al. 2014). Interestingly, in these studies whilst little effect was observed for chemotherapy alone, a combination of therapy with CTLA-4 commonly induced 50\% tumour regression.

PD-1/PD-L1 pathway blockade and low-dose cyclophosphamide also increased tumour immunity (Aston et al. 2014), potentially due to depletion of Treg cells, in solid tumour models. In other cancer models, efficacy of the combination PD-1/ GITR with cisplatin and paclitaxel was greatly enhanced compared to monotherapy treatment (Aston et al. 2014). Combination chemotherapy with PD-1 pathway however is still in the early stages, and only a limited number of drug combinations have been tested in cancer models, and efficacy in mesothelioma is yet to be established.

\section{ICPB and Radiotherapy}

Increasing evidence from both clinical and preclinical settings suggests that radiotherapy may be a useful partner for ICPB, causing beneficial immune modulation and release of tumour-associated antigens but without the systemic toxicities associated with chemotherapy. 
Mouse models of mesothelioma using hypo-fractionated dosing schedules, i.e. 15 Gy delivered over 3 fractions, were used to asses immunological response to radiotherapy. Two subcutaneous tumours, one on each flank, were used, with local radiotherapy to one tumour resulting in increased $\mathrm{T}$ cell infiltration to both tumours (Wu et al. 2015). When anti-CTLA-4 ICPB antibody was added following radiotherapy, tumour growth was delayed, and the presence of suppressive Treg cells was decreased with increased activated CD8 T cells in the spleen; expression of genes linked to immune activation in tumour was also upregulated (Wu et al. 2015). However, as in the clinic, tumour growth was not controlled in the majority of mice, and it may be that treatment scheduling was not optimal; for example, studies in other cancers have demonstrated that administration of anti-CTLA4 prior to radiotherapy may be more efficacious (Twyman-Saint Victor et al. 2015). Local radiotherapy has also been combined with anti-PD-1 and anti-PD-L1 ICPB antibodies in mouse mesothelioma, with both combinations currently showing to be less effective than radiotherapy plus anti-CTLA-4 (De La Maza et al. 2017).

\section{Other Chemotherapy Combination Treatments}

RTKs have a role in mesothelioma, and recent studies indicate that inhibition of the $\mathrm{PI} 3 \mathrm{~K} / \mathrm{AKT}$ pathway enhances sensitivity to chemotherapeutic agents in preclinical studies. Other studies indicate the focal adhesion kinases and PD1 inhibitors may increase anti-tumour immunity (Schunselaar et al. 2016).

Neo-angiogenesis in cancer development provides nutrients to cancer cell proliferation and an avenue for metastasis. Mesothelioma cells secrete VEGF and have enhanced receptor expression to induce new vessel formation. High-level VEGF in patient serum is indicative of dismal mesothelioma prognosis. In combination the VEGF neutralising antibody, bevaciumab, with pemetrexed has shown efficacy in high-expression VEGF xenografts and is thought to control mesothelioma progression (Thellung et al. 2016).

\section{$5 \quad$ Summary}

A number of valuable mesothelioma models are available, each with their own advantages and shortcomings. Currently, mesothelioma mouse models must be selected on the attributes that best suit the specific research question. It is important that findings be replicated in multiple models to determine the reproducibility and robustness of results and increase the translatability of findings.

\section{References}

Arnold DT, Maskell NA. Biomarkers in mesothelioma. Ann Clin Biochem. 2018;55(1):49-58. https://doi.org/10.1177/0004563217741145.

Aston WJ, Fisher SA, Khong A, Mok C, Nowak AK, Lake RA, Joost Lesterhuis W. Combining chemotherapy and checkpoint blockade in thoracic cancer: how to proceed? Lung Cancer Manag. 2014;3(6):443-57. 
Bakker E, Guazzelli A, Ashtiani F, Demonacos C, Krstic-Demonacos M, Mutti L. Immunotherapy advances for mesothelioma treatment. Expert Rev Anticancer Ther. 2017;17(9):799-814. https://doi.org/10.1080/14737140.2017.1358091.

Bayman N, Ardron D, Ashcroft L, Baldwin DR, Booton R, Darlison L, Edwards JG, Lang-Lazdunski L, Lester JF, Peake M, Rintoul RC, Snee M, Taylor P, Lunt C, Faivre-Finn C. Protocol for PIT: a phase III trial of prophylactic irradiation of tracts in patients with malignant pleural mesothelioma following invasive chest wall intervention. BMJ Open. 2016;6(1):e010589. https://doi. org/10.1136/bmjopen-2015-010589.

Belin LJ, Ady JW, Lewis C, Marano D, Gholami S, Mojica K, Eveno C, Longo V, Zanzonico PB, Chen NG, Szalay AA, Fong Y. An oncolytic vaccinia virus expressing the human sodium iodine symporter prolongs survival and facilitates SPECT/CT imaging in an orthotopic model of malignant pleural mesothelioma. Surgery. 2013;154(3):486-95. https://doi.org/10.1016/j. surg.2013.06.004.

Bueno R, Stawiski EW, Goldstein LD, Durinck S, De Rienzo A, Modrusan Z, Gnad F, Nguyen TT, Jaiswal BS, Chirieac LR, Sciaranghella D, Dao N, Gustafson CE, Munir KJ, Hackney JA, Chaudhuri A, Gupta R, Guillory J, Toy K, Ha C, Chen YJ, Stinson J, Chaudhuri S, Zhang N, Wu TD, Sugarbaker DJ, de Sauvage FJ, Richards WG, Seshagiri S. Comprehensive genomic analysis of malignant pleural mesothelioma identifies recurrent mutations, gene fusions and splicing alterations. Nat Genet. 2016;48(4):407-16. https://doi.org/10.1038/ng.3520.

Chee J, Robinson BW, Holt RA, Creaney J. Immunotherapy for lung malignancies: from gene sequencing to novel therapies. Chest. 2017;151(4):891-7. https://doi.org/10.1016/j. chest.2016.10.007.

Cho BC, Feld R, Leighl N, Opitz I, Anraku M, Tsao MS, Hwang DM, Hope A, de Perrot M. A feasibility study evaluating surgery for mesothelioma after radiation therapy: the "SMART" approach for resectable malignant pleural mesothelioma. J Thorac Oncol. 2014;9(3):397-402. https://doi.org/10.1097/JTO.0000000000000078.

Cleo Robinson JNS, Gary Lee YC, Lake RA, Joost Lesterhuis W. Mouse models of mesothelioma: strengths, limitations and clinical translation. Lung Cancer Manag. 2014;3(5). https:// doi.org/10.2217/lmt.14.27.

Creaney J, Dick IM, Segal A, Musk AW, Robinson BW. Pleural effusion hyaluronic acid as a prognostic marker in pleural malignant mesothelioma. Lung Cancer. 2013;82(3):491-8. https://doi. org/10.1016/j.lungcan.2013.09.016.

Creaney J, Ma S, Sneddon SA, Tourigny MR, Dick IM, Leon JS, Khong A, Fisher SA, Lake RA, Lesterhuis WJ, Nowak AK, Leary S, Watson MW, Robinson BW. Strong spontaneous tumor neoantigen responses induced by a natural human carcinogen. Oncoimmunology. 2015;4(7):e1011492. https://doi.org/10.1080/2162402X.2015.1011492.

Davis MR, Manning LS, Whitaker D, Garlepp MJ, Robinson BW. Establishment of a murine model of malignant mesothelioma. Int J Cancer. 1992;52(6):881-6.

De La Maza L, Wu M, Wu L, Yun H, Zhao Y, Cattral M, McCart A, Cho BJ, de Perrot M. In situ vaccination after accelerated hypofractionated radiation and surgery in a mesothelioma mouse model. Clin Cancer Res. 2017;23(18):5502-13. https://doi.org/10.1158/1078-0432. CCR-17-0438.

Fear VS, Tilsed C, Chee J, Forbes CA, Casey T, Solin JN, Lansley SM, Joost Lesterhuis W, Dick IM, Nowak AK, Robinson BW, Lake RA, Fisher SA. Combination immune checkpoint blockade as an effective therapy for mesothelioma. Oncoimmunology. 2018;7(10):e1494111. https:// doi.org/10.1080/2162402X.2018.1494111. eCollection 2018.

Fisher SA, Aston WJ, Chee J, Khong A, Cleaver AL, Solin JN, Ma S, Lesterhuis WJ, Dick I, Holt RA, Creaney J, Boon L, Robinson B, Lake RA. Transient Treg depletion enhances therapeutic anti-cancer vaccination. Immun Inflammation Dis. 2017;5(1):16-28. https://doi.org/10.1002/ iid3.136.

Friedlander PL, Delaune CL, Abadie JM, Toups M, LaCour J, Marrero L, Zhong Q, Kolls JK. Efficacy of CD40 ligand gene therapy in malignant mesothelioma. Am J Respir Cell Mol Biol. 2003;29(3 Pt 1):321-30. https://doi.org/10.1165/rcmb.2002-0226OC. 
Goodglick L, Vaslet CA, Messier NJ, Kane AB. Growth factor responses and protooncogene expression of murine mesothelial cell lines derived from asbestos-induced mesotheliomas. Toxicol Pathol. 1997;25(6):565-73.

Jackaman C, Bundell CS, Kinnear BF, Smith AM, Filion P, van Hagen D, Robinson BW, Nelson DJ. IL-2 intratumoral immunotherapy enhances CD8+ T cells that mediate destruction of tumor cells and tumor-associated vasculature: a novel mechanism for IL-2. J Immunol. 2003;171(10):5051-63.

Lesterhuis WJ, Punt CJ, Hato SV, Eleveld-Trancikova D, Jansen BJ, Nierkens S, Schreibelt G, de Boer A, Van Herpen CM, Kaanders JH, van Krieken JH, Adema GJ, Figdor CG, de Vries IJ. Platinum-based drugs disrupt STAT6-mediated suppression of immune responses against cancer in humans and mice. J Clin Invest. 2011;121(8):3100-8. https://doi.org/10.1172/ JCI43656.

Manning L, Whitaker D, Murch AR, Garlepp MJ, Davis MR, Musk AW, Robinson BW. Establishment and characterization of five human malignant mesothelioma cell lines derived from pleural effusions. Int J Cancer. 1991;47(2):285-90.

Marabelle A, Kohrt H, Sagiv-Barfi I, Ajami B, Axtell RC, Zhou G, Rajapaksa R, Green MR, Torchia J, Brody J, Luong R, Rosenblum MD, Steinman L, Levitsky HI, Tse V, Levy R. Depleting tumor-specific Tregs at a single site eradicates disseminated tumors. J Clin Invest. 2013;123(6):2447-63. https://doi.org/10.1172/JCI64859.

Nowak AK, Lake RA, Marzo AL, Scott B, Heath WR, Collins EJ, Frelinger JA, Robinson BW. Induction of tumor cell apoptosis in vivo increases tumor antigen cross-presentation, cross-priming rather than cross-tolerizing host tumor-specific CD8 T cells. J Immunol. 2003a;170(10):4905-13.

Nowak AK, Robinson BW, Lake RA. Synergy between chemotherapy and immunotherapy in the treatment of established murine solid tumors. Cancer Res. 2003b;63(15):4490-6.

Nusse R, Clevers H. Wnt/beta-catenin Signaling, disease, and emerging therapeutic modalities. Cell. 2017;169(6):985-99. https://doi.org/10.1016/j.cell.2017.05.016.

Opitz I, Weder W. A nuanced view of extrapleural pneumonectomy for malignant pleural mesothelioma. Ann transl Med. 2017;5(11):237. https://doi.org/10.21037/atm.2017.03.88.

Paik PK, Krug LM. Histone deacetylase inhibitors in malignant pleural mesothelioma: preclinical rationale and clinical trials. J Thorac Oncol. 2010;5(2):275-9. https://doi.org/10.1097/ JTO.0b013e3181c5e366.

Pease DF, Kratzke RA. Oncolytic viral therapy for mesothelioma. Front Oncol. 2017;7:179. https://doi.org/10.3389/fonc.2017.00179.

Perrot M, Wu L, Wu M, Cho BCJ. Radiotherapy for the treatment of malignant pleural mesothelioma. Lancet Oncol. 2017;18(9):e532-42. https://doi.org/10.1016/S1470-2045(17)30459-X.

Ramakrishnan R, Assudani D, Nagaraj S, Hunter T, Cho HI, Antonia S, Altiok S, Celis E, Gabrilovich DI. Chemotherapy enhances tumor cell susceptibility to CTL-mediated killing during cancer immunotherapy in mice. J Clin Invest. 2010;120(4):1111-24. https://doi. org/10.1172/JCI40269.

Ramos-Nino ME, Testa JR, Altomare DA, Pass HI, Carbone M, Bocchetta M, Mossman BT. Cellular and molecular parameters of mesothelioma. J Cell Biochem. 2006;98(4):723-34. https://doi.org/10.1002/jcb.20828.

Robinson BW, Lake RA. Advances in malignant mesothelioma. N Engl J Med. 2005;353(15):1591603. https://doi.org/10.1056/NEJMra050152.

Robinson C, van Bruggen I, Segal A, Dunham M, Sherwood A, Koentgen F, Robinson BW, Lake RA. A novel SV40 TAg transgenic model of asbestos-induced mesothelioma: malignant transformation is dose dependent. Cancer Res. 2006;66(22):10786-94. https://doi. org/10.1158/0008-5472.CAN-05-4668.

Robinson C, Walsh A, Larma I, O'Halloran S, Nowak AK, Lake RA. MexTAg mice exposed to asbestos develop cancer that faithfully replicates key features of the pathogenesis of human mesothelioma. Eur J Cancer. 2011;47(1):151-61. https://doi.org/10.1016/j.ejca.2010.08.015. 
Robinson C, Dick IM, Wise MJ, Holloway A, Diyagama D, Robinson BW, Creaney J, Lake RA. Consistent gene expression profiles in MexTAg transgenic mouse and wild type mouse asbestos-induced mesothelioma. BMC Cancer. 2015;15:983. https://doi.org/10.1186/ s12885-015-1953-y.

Rusch VW, Giroux D, Kennedy C, Ruffini E, Cangir AK, Rice D, Pass H, Asamura H, Waller D, Edwards J, Weder W, Hoffmann H, van Meerbeeck JP, Committee IS. Initial analysis of the international association for the study of lung cancer mesothelioma database. J Thorac Oncol. 2012;7(11):1631-9. https://doi.org/10.1097/JTO.0b013e31826915f1.

Santarelli L, Staffolani S, Strafella E, Nocchi L, Manzella N, Grossi P, Bracci M, Pignotti E, Alleva R, Borghi B, Pompili C, Sabbatini A, Rubini C, Zuccatosta L, Bichisecchi E, Valentino M, Horwood K, Comar M, Bovenzi M, Dong LF, Neuzil J, Amati M, Tomasetti M. Combined circulating epigenetic markers to improve mesothelin performance in the diagnosis of malignant mesothelioma. Lung Cancer. 2015;90(3):457-64. https://doi.org/10.1016/j. lungcan.2015.09.021.

Schunselaar LM, Quispel-Janssen JM, Neefjes JJ, Baas P. A catalogue of treatment and technologies for malignant pleural mesothelioma. Expert Rev Anticancer Ther. 2016;16(4):455-63. https://doi.org/10.1586/14737140.2016.1162100.

Shapiro IM, Kolev VN, Vidal CM, Kadariya Y, Ring JE, Wright Q, Weaver DT, Menges C, Padval M, McClatchey AI, Xu Q, Testa JR, Pachter JA. Merlin deficiency predicts FAK inhibitor sensitivity: a synthetic lethal relationship. Sci Transl Med. 2014;6(237):237ra268. https://doi. org/10.1126/scitranslmed.3008639.

Sharabi AB, Lim M, DeWeese TL, Drake CG. Radiation and checkpoint blockade immunotherapy: radiosensitisation and potential mechanisms of synergy. Lancet Oncol. 2015;16(13):e498-509. https://doi.org/10.1016/S1470-2045(15)00007-8.

Steven A, Fisher SA, Robinson BW. Immunotherapy for lung cancer. Respirology. 2016;21(5):821-33. https://doi.org/10.1111/resp.12789.

Taguchi T, Jhanwar SC, Siegfried JM, Keller SM, Testa JR. Recurrent deletions of specific chromosomal sites in $1 \mathrm{p}, 3 \mathrm{p}, 6 \mathrm{q}$, and $9 \mathrm{p}$ in human malignant mesothelioma. Cancer Res. 1993;53(18):4349-55.

Thellung S, Favoni RE, Wurth R, Nizzari M, Pattarozzi A, Daga A, Florio T, Barbieri F. Molecular pharmacology of malignant pleural mesothelioma: challenges and perspectives from preclinical and clinical studies. Curr Drug Targets. 2016;17(7):824-49.

Twyman-Saint Victor C, Rech AJ, Maity A, Rengan R, Pauken KE, Stelekati E, Benci JL, Xu B, Dada H, Odorizzi PM, Herati RS, Mansfield KD, Patsch D, Amaravadi RK, Schuchter LM, Ishwaran H, Mick R, Pryma DA, Xu X, Feldman MD, Gangadhar TC, Hahn SM, Wherry EJ, Vonderheide RH, Minn AJ. Radiation and dual checkpoint blockade activate non-redundant immune mechanisms in cancer. Nature. 2015;520(7547):373-7. https://doi.org/10.1038/ nature 14292.

Wu L, Wu MO, De la Maza L, Yun Z, Yu J, Zhao Y, Cho J, de Perrot M. Targeting the inhibitory receptor CTLA-4 on T cells increased abscopal effects in murine mesothelioma model. Oncotarget. 2015;6(14):12468-80. https://doi.org/10.18632/oncotarget.3487.

Zeltsman M, Dozier J, McGee E, Ngai D, Adusumilli PS. CAR T-cell therapy for lung cancer and malignant pleural mesothelioma. Transl Res. 2017;187:1-10. https://doi.org/10.1016/j. $\operatorname{trs1.2017.04.004.~}$ 